\title{
Errors in Surgical Pathology Reports: a Study from a Major Center in Pakistan
}

\author{
Zubair Ahmad*, Romana Idrees, Nasir Uddin, Arsalan Ahmed, Saira Fatima
}

\begin{abstract}
Background: Errors in surgical pathology diagnosis can have serious consequences for the patient. Since the final product of a surgical pathology lab is the report, errors can be picked by reviewing reports of cases. Aim: To determine the frequency and types of error in surgical pathology reports of cases signed out in 2014 in a laboratory in Karachi, Pakistan. Materials and Methods: All surgical pathology reports in which changes were made in the original report after sign out and an amended report was issued were included. Errors included: (1) misinterpretations; (2) missing critical information; (3) erroneous critical information; (4) misidentification; and (5) typographic errors. Results: Errors were identified in 210 cases $(0.37 \%)$. These comprised 199 formalin fixed specimens and 11 frozen sections. The latter represented $3.8 \%$ of a total of 2,170 frozen sections. Of the 11 frozen section errors, 10 were misinterpretations. Of the 199 permanent specimens, $99(49.7 \%)$ were misinterpretations, $65(32.7 \%)$ belonged to missing critical information category, $8(4 \%)$ belonged to erroneous critical information category, $8(4 \%)$ were misidentifications, $16(8 \%)$ were typographic errors while 3 cases $(1.5 \%)$ were other errors. Most misinterpretations occurred in the gastro intestinal, liver and pancreato biliary tract (23.2\%) and breast (13.1\%). Another 87 cases were reviewed on the clinicians' request. However diagnosis after review remained the same as the original diagnosis. In 49 out of these $(56.3 \%)$, additional workup was performed at the time of the review. Conclusions: Our findings were similar to other published studies. We need to develop documented procedures for timely review of cases to detect errors.
\end{abstract}

Keywords: Surgical pathology - amended reports - errors - misinterpretations - omission of critical information

Asian Pac J Cancer Prev, 17 (4), 1869-1874

\section{Introduction}

Errors in surgical pathology diagnosis can have serious consequences for the patient. Since the principal product of surgical pathology laboratory is the report, errors are mostly picked by reviewing reports of cases that have been dispatched. Errors are either picked by clinicians when the reports do not match the clinical diagnosis or by the pathologists themselves. The pathologists discover the error either by mandatory reviews of the slides and reports at the time of case referral to another institution for second opinion, or when reviewing the slides for a surgical pathology conference especially tumor boards or during regular audit of surgical pathology cases as part of a routine quality assurance exercise. The pathologists can also discover the error when reviewing the permanent sections of a case reported initially as a frozen section. Errors in surgical pathology can be major or clinically significant if they have adverse effects on the patient's clinical management and minor or clinically insignificant if they do not have adverse consequences on the patient's clinical management.

Errors in surgical pathology can be misinterpretations which include false positives or false negatives, errors in determining the biologic behavior of tumors whether benign or malignant or errors in determining the histogenesis of tumors. Errors can also be misidentifications of the patient, tissue, specimen laterality and/or errors in identification of anatomic localization of the specimen. Errors in surgical pathology reports also include the omission of critical information or inclusion of wrong information in the reports. Another common type of error in repots are typographical errors such as those of spellings, grammar, formatting etc.

All errors when discovered lead to a review of the case and any changes, corrections etc. are then issued as amended or addendum reports. In some cases, clinicians are not satisfied by the reports and request the pathologists to review the case. If on review, without or after additional workup, no error is detected and the original report stands, the fact is communicated in the form of an addendum report.

The aim of this study was to determine the frequency and types of errors in surgical pathology reports of cases signed out in 2014. The Section of Histopathology at Aga Khan University Hospital (AKUH) in Karachi is the 
largest in Pakistan and we get specimens from all over the country. (Ahmad et al., 2014)

\section{Materials and Methods}

All surgical pathology reports signed out in 2014 in which changes were made in the original report to correct errors of any type after the case led been signed out and in which an amended report was subsequently issued, were included in the study. In addition, all those reports where after sign-out case was reviewed on the clinician's request but the diagnosis after review remained unchanged (with or without additional workup) and in which an addendum report was issued to document the same, were also included in the study. Errors in surgical pathology reports were classified as follows:

1. Misinterpretations defined as inaccurate or incorrect diagnosis. These included those in which change in diagnosis occurred on the review of the case without performing any additional workup - "per se",; as well as those misinterpretations which occurred as a result of failure to perform appropriate immunohistochemical (IHC) and/ or special stains, failure to submit and examine appropriate sections, failure to submit and examine adequate number of sections, failure to perform and examine deeper levels etc. at the time of the original sign out and which when performed at the time of review led to a significant change in diagnosis.

2. Missing critical information in reports defined as information the omission of which in surgical pathology reports was likely to have significant adverse impact on patient care. Examples include missing critical measurements such as distance of tumor from excision margins in malignant neoplasms, margin status i.e. positive or negative, missing tumor grade or stage, missing tumor size and other critical information for example omission of status of nodes or adnexal involvement in endometrial carcinoma, omission of status of detrusor muscle involvement in urothelial carcinomas of urinary bladder, omission of information about extra prostatic extension in prostatic adenocarcinoma on radical prostatectomy specimens etc. Non neoplastic examples include omission of status of fungal stain in nasal polyps, omission of information regarding presence or absence of Helicobacter pylori in gastric mucosal biopsies etc.
3. Erroneous critical information was defined as erroneous information the inclusion of which in surgical pathology reports was likely to have significant adverse on patient care. Examples include the incorrect tumor grade or stage, incorrect tumor size etc.

4. Misidentifications defined as errors in identifying a tissue correctly or errors made in determining the laterality of a specimen.

5. Typographic errors defined as spelling or grammatical errors which could lead to misinterpretation of surgical pathology reports. Computer formatting errors were also included in this category.

The data was reviewed by the two principal authors (ZA and RI).All data was recorded and analyzed using the SPSS 19.0 software package. Cytology specimens were not included in the study.

\section{Results}

A total of 57000 surgical pathology cases were signed out in 2014.A total of 297 reports were included in the study. Errors in surgical pathology reports were identified in 210 cases or $0.37 \%$. These 210 cases included 11 cases in which frozen sections were requested and there were discrepancy between the original diagnosis rendered on frozen section and the final diagnosis given on permanent section. The total number of frozen section cases during the year was 2170 (out of 57000) or 3.8\%. The discordance rate on frozen section cases was $0.51 \%$. In addition to the 210 cases in which errors were identified, another 87 were reviewed on clinicians' request. However, the diagnosis after review remained the same as the original diagnosis. In 49 out of these 87 cases $(56.3 \%)$ additional workup was performed (for example deeper levels, additional sections, special stains, immunohistochemical stains etc. However, this additional workup did not result in a change in diagnosis. In 38 out of 87 cases $(43.7 \%)$, cases were reviewed but no additional workup was done and there was no change in diagnosis as a result of the review. Out of 11 frozen section errors, 10 were interpretative errors or misinterpretations (Table 1 ) while in 1 case, a focus of carcinoma was seen in a sentinel node (from a patient with carcinoma breast) on deeper permanent level. A diagnosis of "negative for metastasis" had been rendered at the time of frozen section .All 11 frozen section errors were picked

Table 1. Frozen Section Errors (Misinterpretations) in 2014 (Total Number of Frozen Sections Reported: 2170)

\begin{tabular}{|c|c|c|c|}
\hline S.No. & Tissue/Organ & Frozen Section Diagnosis & Final Diagnosis (on permanent sections) \\
\hline 1 & Central Nervous System & Meningioma & Myxopapillary Ependymoma \\
\hline 2 & Lymph Node & Reactive lymph node & $\begin{array}{l}\text { Low grade Bcell lymphoproliferative } \\
\text { disorder }\end{array}$ \\
\hline 3 & Central Nervous System & High grade glioma & Metastatic carcinoma \\
\hline 4 & $\begin{array}{l}\text { Head \&Neck. Tongue Squamous } \\
\text { cell carcinoma: Margins }\end{array}$ & Margins: dysplastic & Margins: benign(no dysplasia seen) \\
\hline 5 & Central Nervous System & low grade glioma & High grade glioma \\
\hline 6 & Ovary & Benign serous cystadenoma & Borderline serous neoplasm* \\
\hline 7 & Central Nervous System & Inflammation & Lymphoproliferative disorder \\
\hline 8 & Central Nervous System & Lymphoproliferative disorder & High grade glioma \\
\hline 9 & $\begin{array}{l}\text { Head \& Neck. Cheek Squamous } \\
\text { cell carcinoma: Margins }\end{array}$ & Margins: dysplastic & Margins: benign(no dysplasia seen \\
\hline 10 & Peritoneal nodule & Atypical cells seen(signet ring cells) & Plasma cells(no atypical cells seen) \\
\hline
\end{tabular}


Table 2. Errors Identified in Paraffin Embedded Specimen Reports. $(\mathbf{n = 1 9 9 )}$

\begin{tabular}{|c|c|c|c|}
\hline S. No. & Error type & Number & Percentage $(\%)$ \\
\hline 1 & Misinterpretation due to failure to perform appropriate IHC stains & 24 & $12.10 \%$ \\
\hline 2 & Misinterpretation due to failure to perform appropriate special stains & 7 & $3.50 \%$ \\
\hline 3 & $\begin{array}{l}\text { Misinterpretation due to failure to submit appropriate/adequate sections for histologic } \\
\text { examination }\end{array}$ & 25 & $12.60 \%$ \\
\hline 4 & Misinterpretation due to failure to perform adequate deeper level/s & 13 & $6.50 \%$ \\
\hline 5 & Misinterpretation per se i.e. not due to lack of any appropriate workup & 30 & $15.10 \%$ \\
\hline 6 & Missing critical /important information in reports & 65 & $32.70 \%$ \\
\hline 7 & Erroneous critical /important information & 8 & $4.00 \%$ \\
\hline 8 & Typographic errors & 16 & $8.00 \%$ \\
\hline 9 & Wrong identification/coding or laterality of tissue & 8 & $4.00 \%$ \\
\hline 10 & Wrong diagnostic term used & 1 & $0.50 \%$ \\
\hline 11 & Specimen not reported at all & 2 & $1 \%$ \\
\hline
\end{tabular}

Table 3. Examples of Misinterpretations Occurring as a Result of Failure to Perform Appropriate IHC Stains

\begin{tabular}{cccc}
\hline S.no. & Original diagnosis & Corrected diagnosis & IHC stains performed on case review \\
\hline 1 & High grade Glioma & Metastatic poorly differentiated carcinoma & CK AE1/AE3 positive, CK CAM 5.2 \\
positive & Blastoid variant of Mantle cell lymphoma & CD20,LCA Positive, MUM1,CD56 \\
2 & Diffuse large B Cell Lymphoma & Negative & Calretinin,WT1,CK5/6 positive. TTF1 \\
3 & Plasma cell neoplasm & Diffuse large B Cell Lymphoma & Negative \\
4 & Poorly differentiated carcinoma & Malignant Mesothelioma & TTF1:Negative, CK20:Positive \\
5 & Lung Adenocarcinoma & Colon carcinoma &
\end{tabular}

Table 4. Examples of Misinterpretations Occurring as a Result of Failure to Perform Appropriate Special Stains /Adequate Deeper Levels

\begin{tabular}{|c|c|c|c|}
\hline $\begin{array}{l}\text { S. } \\
\text { No. }\end{array}$ & Original diagnosis & Corrected diagnosis & $\begin{array}{c}\text { Special stains performed on case } \\
\text { review }\end{array}$ \\
\hline 1 & Nasal polyp (fungal stains not performed) & Polyp along with septate fungal hyphae & PAS/PASD Positive \\
\hline 2 & Nasal polyp (fungal stains not performed) & Polyp along with septate fungal hyphae & PAS/PASD Positive \\
\hline 3 & $\begin{array}{l}\text { Reactive gliosis brain (fungal stains not } \\
\text { done) }\end{array}$ & septate fungal hyphae seen & PAS/PASD Positive \\
\hline 4 & $\begin{array}{c}\text { Cecal biopsy No granuloma on initial slide } \\
\text { (level not done) }\end{array}$ & $\begin{array}{l}\text { Granuloma seen on deeper levels. } \\
\text { Possibility of Tuberculosis raised. }\end{array}$ & $\begin{array}{l}\text { Deeper level was performed on } \\
\text { case review. }\end{array}$ \\
\hline 5 & $\begin{array}{l}\text { Rectal polyp. No adenomatous change on } \\
\text { initial section(no level performed) }\end{array}$ & $\begin{array}{l}\text { Adenomatous change was seen on } \\
\text { deeper levels. Tubular Adenoma }\end{array}$ & $\begin{array}{c}\text { Deeper level was performed on } \\
\text { case review. }\end{array}$ \\
\hline 6 & $\begin{array}{c}\text { Gastric biopsy from mass in stomach No } \\
\text { atypical cells seen }\end{array}$ & $\begin{array}{l}\text { Atypical cells seen on deeper levels. } \\
\text { Diagnosis of carcinoma was given }\end{array}$ & $\begin{array}{l}\text { Deeper levels and Mucin stain } \\
\text { were performed on case review. }\end{array}$ \\
\hline 7 & $\begin{array}{l}\text { Colon biopsy for ganglion cells No ganglion } \\
\text { cells seen on initial two levels. }\end{array}$ & $\begin{array}{c}\text { ganglion cells seen on multiple deeper } \\
\text { levels }\end{array}$ & $\begin{array}{l}\text { Multiple deeper levels performed } \\
\text { on case review. }\end{array}$ \\
\hline
\end{tabular}

Table 5. Examples of Misinterpretations Occurring as a Result of Failure to Submit Appropriate/Adequate Sections for Microscopic Examination

\begin{tabular}{|c|c|c|c|}
\hline $\begin{array}{l}\text { S. } \\
\text { No. }\end{array}$ & Original Diagnosis & Corrected Diagnosis & $\begin{array}{c}\text { Additional sections submitted at time } \\
\text { of review }\end{array}$ \\
\hline 1 & Breast Carcinoma T2NO & Breast Carcinoma T2N1 & $\begin{array}{l}\text { Missed at time of initial gross, nodes } \\
\text { positive }\end{array}$ \\
\hline 2 & Gall bladder, Chronic cholecystitis & $\begin{array}{l}\text { Adenoma with low grade } \\
\text { dysplasia }\end{array}$ & Polyp missed at the time of initial gross \\
\hline 3 & Ovarian Serous cystadenoma & Borderline serous tumor & $\begin{array}{l}\text { Additional sections revealed borderline } \\
\text { areas, but no stromal invasion seen. }\end{array}$ \\
\hline 4 & Breast specimen: lesion missed at initial gross & Carcinoma ,T1N0 & $\begin{array}{l}\text { Lesion seen and section submitted at } \\
\text { time of review }\end{array}$ \\
\hline 5 & $\begin{array}{l}\text { Urinary Bladder Carcinoma, Urothelial high } \\
\text { grade;Detrussor muscle not identified in the } \\
\text { original multiple sections }\end{array}$ & $\begin{array}{l}\text { Invasive papillary urothelial } \\
\text { carcinoma }\end{array}$ & $\begin{array}{l}\text { Additional sections reveal detrusor } \\
\text { muscle involved by the tumor }\end{array}$ \\
\hline 6 & $\begin{array}{l}\text { Breast carcinoma, DCIS.No invasion seen in } \\
\text { multiple sections submitted. }\end{array}$ & $\begin{array}{l}\text { Invasive Ductal carcinoma, } \\
\text { NOS }\end{array}$ & $\begin{array}{c}\text { Additional sections reveal areas of } \\
\text { invasion }\end{array}$ \\
\hline 7 & $\begin{array}{c}\text { Carcinoma oral cavity; sections from bone not } \\
\text { submitted }\end{array}$ & $\begin{array}{l}\text { Tumor invades through corti- } \\
\text { cal bone }\end{array}$ & $\begin{array}{l}\text { Sections from bone were submitted and } \\
\text { show involvement by tumor. }\end{array}$ \\
\hline
\end{tabular}


Table 6. Examples of Misinterpretations Occurring Per Se

\begin{tabular}{ccc}
\hline S. No. & Original Diagnosis & Corrected Diagnosis(without any additional workup) \\
\hline 1 & Pancreas; Mixed ductal and endocrine tumor & Chronic Pancreatitis \\
2 & Breast; invasive lobular carcinoma on core biopsy & invasive ductal carcinoma on mastectomy specimen \\
3 & Colon endoscopic biopsy: Non specific colitis & Inflammatory Bowel Disease(ulcerative colitis) \\
4 & Thigh muscle: Neurofibroma & Spindle cell lipoma \\
5 & Bronchial biopsy: Tuberculosis & Sarcoidosis \\
6 & Spinal meninges: Arachnoid cyst & Enterogenous cyst(Neuroenteric cyst) \\
7 & Bone: fracture changes & Benign bone cyst \\
8 & Gastrointestinal tract: Nonspecific colitis & Amyloidosis \\
9 & Brain: Oligodendroglioma,WHO grade 2 & Anaplastic Oligodendroglioma,WHO grade 3 \\
10 & Duodenum: mild nonspecific duodenitis & Brunner's gland hyperplasia \\
11 & Skin biopsy: Atopic dermatitis & Neonatal SLE(systemic lupus erythematosus) \\
12 & Endometrial curretings: Exogenous hormonal effect & Excessive estrogen effect (Exogenous hormones not given) \\
\hline
\end{tabular}

Table 7. Distribution of Misinterpretations in Various Organs (n=99)

\begin{tabular}{|c|c|c|c|}
\hline S. No. & Organ/System & Number & Percentage $(\%)$ \\
\hline 1 & Gastrointestinal tract(including liver,pancreas \& biliary tract) & 23 & $23.20 \%$ \\
\hline 2 & Breast & 13 & $13.10 \%$ \\
\hline 3 & Lungs,pleura,mediastinum & 10 & $10.10 \%$ \\
\hline 4 & Lymph nodes & 9 & $9.10 \%$ \\
\hline 5 & Head \& Neck (including nasal, paranasal sinuses, salivary gland, oral cavity, gums etc.) & 9 & $9.10 \%$ \\
\hline 6 & Kidney \&urinary bladder & 8 & $8.10 \%$ \\
\hline 7 & Female genital tract & 8 & $8.10 \%$ \\
\hline 8 & Bone and Soft tissue & 7 & $7.10 \%$ \\
\hline 9 & Brain & 6 & $6.10 \%$ \\
\hline 10 & Skin & 4 & $4.00 \%$ \\
\hline 11 & Male Genital Tract & 2 & $2.00 \%$ \\
\hline
\end{tabular}

by the pathologist when reviewing the permanent sections.

The remaining 199 cases in which errors occurred were all paraffin embedded specimens. The large majority of these, 180 cases out of 199(90.5\%), were detected when clinicians requested a review. Only $19(9.5 \%)$ were detected by the pathologist who reported the case.

Borderline features were seen in the permanent section of the original section submitted at the time of frozen section as well as in the additional sections submitted subsequently. However, in these cases no evidence of invasion was seen in any of the sections provided by the Pathologuist.

Out of 199 cases, 99 (49.7\%) errors occurred as a result of misinterpretations. These included errors in which misinterpretations occurred as a result of failure to perform appropriate immunohistochemical (IHC) stains and /or special stains, failure to submit and examine adequate number of sections, failure to perform deeper levels etc., all of which led to major changes in diagnosis. In addition, a number of cases were misinterpreted per se that is review of the cases on the clinicians' request led to a change in diagnosis based on the workup originally performed without the need for performing any additional workup. In 65 cases $(32.7 \%)$, critical /important information was missing in the reports which was later added. Another important group was that of typographical errors which accounted for 16 cases (8\%).The details of these errors are shown in Table 2.

Examples of misinterpretations occurring as a result of failure to perform appropriate IHC stains are shown in Table 3. Examples of misinterpretations occurring as a result of failure to perform appropriate special stains / adequate deeper levels are shown in Table 4. Examples of misinterpretations occurring as a result of failure to submit appropriate /adequate sections for microscopic examination are shown in Table 5. Examples of misinterpretations occurring per se are shown in Table 6 . Distribution of interpretation errors (misinterpretations) in various organs of the body is given in Table 7 .

\section{Discussion}

Recently, the College of American Pathologists and the Association of Directors of Anatomic and Surgical Pathology formed an expert panel which was asked to formulate recommendations based on existing evidence that additional case reviews of surgical pathology and cytology cases detect diagnostic errors. The panel drafted five recommendations for which there was strong agreement between the members. The first of these recommendations was that anatomic pathologists should develop documented procedures for timely review of selected cases to detect errors and should monitor and document the results of these reviews, and in case serious errors are detected, take steps to reduce the same.(Nakhleh et al., 2015).

Zarbo et al. (2005) identified five general mechanisms by which errors can be detected which include pathologist reviewing the case without additional information, with additional information, while preparing for a clinicopathologic conference, review on clinician's request, or as a result of external consultation.Our present study was a post sign out audit which has both advantages and disadvantages.(Smith and Raab, 2012) Studies have noted higher error detection rates with retrospective reviews (Renshaw and Gould, 2006 Smith and Raab, 2012). Diagnostic disagreements in surgical pathology have ranged between $2.2 \%$ to $6.9 \%$ in some 
studies (Renshaw and Gould, 2006). Overall error rates and clinically significant error rates have ranged from 0 to $2.36 \%$ and $0.34 \%$ to $1.19 \%$ respectively ( Renshaw et al., 2003). We used the terms or taxonomy proposed by Meir et al (2011) in our study. However, we took some liberty with the terminology and modified the terms to make them more relevant to our practice setting.

A glance at Table 2 shows that almost half (just under $50 \%$ ) of all errors in our study were misinterpretations. This is a high figure which compares unfavorably with figures such as $14.6 \%$ and as low as $0.07 \%$ reported by various recent studies.(Volmer et al., 2014; Chaudhary et al., 2014) One of these studies found that overall defect rates were higher in institutions with surgical pathology training (residency) programs.(Volmer et al., 2014) Some plausible explanations for high rate of misinterpretive errors in our practice include excessive workload and pressure on the pathologists to sign out cases quickly. Ratio of surgical pathologist in Pakistan compared to the number of cases is very low compared to international standards. Lack of subspecialty practice (for the same reason) and a busy surgical pathology residency program are some of the other possible causes. Due to shortage of surgical pathologists in the country, a surgical pathologist reports everything from skin to lymph nodes, from breast to CNS, from liver to kidney and so on. The same practice is followed in our institution too. All of us report everything. However, as each of us have sub specialty interests, difficult cases in every organ system are shown to the expert/s in that particular sub specialty as a mandatory second opinion before sign out. This regular practice on the whole works very well and acts as a safety valve.

However, on some occasions, few cases 'slip through the net' of this safety valve and may result in misinterpretations. Such lacunae or omissions in seeking mandatory second opinion in difficult cases are especially likely to occur in the summer month when a number of faculty members are on vacations. This lack of sub specialty practice will remain until there are sufficient surgical pathologists to allow each to practice within his/ her specialized domain. A glance at tables 4 and 5 shows that many of the misinterpretations occurred as a result of failure to perform and examine deeper levels and/or special stains, failure to submit and examine adequate sections etc which point towards the problems discussed above. However, our results must be put in their proper perspective - misinterpretations occurred in $0.18 \%$ cases out of a total of 57,000 cases (including $0.36 \%$ of 2170 frozen sections).

Any changes made in our reports (after discovery of error) are reported as "addendum reports". However we use the term "amended report "when misinterpretations are involved. Even today, considerable confusion exists among pathologists regarding appropriate use of these designations especially if the changes are minor or "lesser changes". However, most agree that a major change in diagnosis should be designated as an "amendment". (Cooper, 2006; Nakhleh et al., 2006) A study by Finkelstein et al in 2012 reported that the number of cases with addendum reports increased from $0.9 \%$ in 1993 to as high as $8.6 \%$ in 2008 and that $5.6 \%$ of addendum reports had information which should have been reported as an "amended" rather than as "addendum" report.(Finkelstein et al., 2012)

The large majority of cases in our study were reviewed on the clinician's request. Although a large Q-probe study of amended reports also showed that clinician requested reviews was the most common form of review, the percentage of such cases $(20.5 \%)$ was very low compared to our study in which $90.5 \%$ cases were clinician requested reviews.(Nakhleh and Zarbo, 1998)

Omission of critical/important information was a major cause for errors in our surgical pathology reports accounting for $32.7 \%$ of all errors (Table 2). Many of the same reasons which are given above to explain the high percentage of misinterpretations can also be applicable to "errors of omissions". However, we feel that the frequency of such errors in our practice has consistently declined especially since we switched to a synoptic/checklist format for the reporting of cancer resection specimens and will continue to decline in the future.

Typographic errors were also quite common in our setting (Table 2). Some of the causative factors include lack of english language proficiency of transcribers (and even residents), lack of synoptic /structured reporting format for many neoplastic lesions (specimens other than resections) and non-neoplastic lesions.

As described by Roy and Hunt, examination of amended reports (as in current study) is one of the various methods that are available for detecting errors in surgical pathology.(Roy and Hunt, 2010) The methods that we use for detection of errors include intradepartmental consultation with one or more colleagues or intradepartmental consultation in the Departmental Consultation Conference which is held daily and in which multiple pathologists participate and give input on difficult and challenging cases. These methods detect errors before the case is signed out. Methods used for detecting errors after cases have been reported include diagnostic review for tumor boards, clinicopathologic conferences etc. and when cases are reviewed at the time when a request for slides/blocks come from clinicians or patients for getting the case reviewed at another institution.

A look at Table 1 shows that misinterpretations of CNS lesions are the commonest errors made during Frozen Sections. Although we now see a large number of neuropathology cases and some of us have subsepciality neuropathology interest and training,(Ahmad et al., 2010) these errors occurred mainly in evening hours when a pathologist with subspeciality interest in neuropathology was not available.

A look at Table 7 shows that the greatest number of errors occurred in specimens from gastrointestinal tract (which also included liver, biliary tract and pancreas) followed by breast. We see a large number of cases from Gastrointestinal tract, liver and biliary tract and pancreas with extremely high rates of cancer in all these organs. (Ahmad et al., 2013; Ahmad et al., 2015) Specimens from lungs and other thoracic structures, lymph nodes and head and neck followed by specimens from urinary system and female genital tract were also quite prone to errors. Studies have also shown the propensity of gastrointestinal tract, 
female genital tract, head and neck etc for errors.(Volmer et al., 2014; Chaudhary et al., 2014)

A percentage of interpretative errors in our series resulted at least partially from lack of relevant clinical information. It has been shown that $0.73 \%$ cases in surgical pathology require relevant clinical information for accurate diagnosis and a significant change in diagnosis occurs in over $60 \%$ such cases when the relevant clinical information is obtained.(Nakhleh et al., 1999) A good and alert clinician who reads a report carefully and in detail can be of great help in discovering errors in cases which have already been signed out.

Our findings were similar to other published studies. We need to develop documented procedures for timely review of cases to detect errors and monitor and document the result of these reviews and take steps to reduce errors.

\section{References}

Ahmad Z, Arshad H, Hasan SH, et al (2011). CNS neoplasms in Pakistan, a pathological perspective. Asian Pac J Cancer Prev, 12, 317-21

Ahmad Z, Arshad H, Fatima S, et al (2013). Gastrointestinal, liver and biliary tract pathology: a histopathological and epidemiological perspective from Pakistan with a review of the literature. Asian Pac J Cancer Prev, 14, 6997-7005

Ahmad Z, Din NU, Minhas K, et al (2015). Epidemiologic data, tumor size, histologic tumor type and grade, pathologic staging and follow up in cancers of the ampullary region and head of pancreas in 311 whipple resection specimens of pakistani patients. Asian Pac J Cancer Prev, 16, 7541-6

Ahmad Z, Idrees R, Fatima S, et al (2014). How our practice of histopathology, especially tumour pathology has changed in the last two decades: reflections from a major referral center in Pakistan. Asian Pac J Cancer Prev, 15, 3829-49.

Chaudhary S, Kahn LB, Bhuiya T (2014). Retrospective blinded review of interpretational diagnostic discrepancies in Surgical Pathology: 18 years of experience at a tertiary care facility. Ann Clin Lab Sci, 44, 469-75

Cooper K (2006). Errors and error rates in Surgical Pathology: An Association of Directors of Anatomic and Surgical Pathology survey. Arch Pathol Lab Med, 130, 607-9.

Finkelstein A, Levy GH, Cohen P, et al (2012). Addenda in pathology reports: trends and their implications. Am J Clin Pathol, 137, 606-11.

Meier FA, Varney RC, Zarbo RJ (2011). Study of amended reports to educate and improve surgical pathology processes. Adv Anat Pathol, 18, 406-13

Nakhleh RE, Zarbo RJ (1998). Amended reports in surgical pathology and implications for diagnostic error reduction and avoidance: a college of american pathologists q-probes study of 1,667,547 accessioned cases in 359 laboratories. Arch Pathol Lab Med, 122, 303-9.

Nakhleh RE, Gephardt G, Zarbo RJ (1999). Necessity of clinical information in surgical pathology: a College of American Pathologist Q-probes study of 771,475 surgical pathology cases from 341 institutions. Arch Pathol Lab Med, 123, 615-9.

Nakhleh R, Coffin C, Cooper K (2006). (For the Association of Directors of Anatomic and Surgical Pathology) Recommendations for quality assurance and improvement in surgical and autopsy pathology. Hum Pathol, 37, 985-8.

Nakhleh RE, Nose V, Colasacco C, et al (2015). Interpretive diagnostic error reduction in surgical pathology and cytology: guideline from the collage of american pathologists pathology and laboratory quality center and the association of directors of anatomic and surgical pathology. Arch Pathol Lab Med, 12.

Renshaw AA, Young ML, Jiroutek MR (2003). Many cases need to be reviewed to compare performance in surgical pathology? Am J Clin Pathol, 119, 388-91.

Renshaw AA, Gould EW (2006). Correlation of workload with disagreement and amendment rates in surgical pathology and nongynecologic cytology. Am J Clin Pathol, 125, 820-2.

Roy JE, Hunt JL (2010). Detection and classification of diagnostic discrepancies (errors) in surgical pathology. $A d v$ Anat Pathol, 17, 359-65.

Smith ML, Raab SS (2012). Directed peer review in surgical pathology. Adv Anat Pathol, 19, 331-7.

Volmer KE, Idowu MO, Hunt JL, et al (2014). Surgical pathology report defects. a college of american pathologists q-probes study of 73 institutions. Arch Pathol Lab Med, 138, 602-12.

Zarbo RJ, Meier FA, Raab SS (2005). Error detection in anatomic pathology. Arch Pathol Lab Med, 129, 1237-45. 